\title{
Electrically Conductive Bioplastics from Cassava Starch
}

\author{
Alvaro A. Arrieta, *,a Piedad F. Gañán, ${ }^{b}$ Samith E. Márquez ${ }^{a}$ and Robin Zuluaga ${ }^{b}$ \\ ${ }^{a}$ Development and Application of New Materials Group (DANM)-Basic Science, \\ Pontificia Bolivariana University, km. 8 Road to Cereté Montería, Córdoba, Colombia \\ ${ }^{b}$ New Materials Research Group, School of Engineering, Mechanical Engineering Program, \\ Pontificia Bolivariana University, Circular 1 \# 70-01, Medellín, Colombia
}

\begin{abstract}
No presente trabalho, biofilmes condutores foram sintetizados através de soluções de $100 \mathrm{~mL}$ de água com $3 \mathrm{~g}$ de amido de mandioca (Manihot esculenta Crantz) e quantidades diferentes de glicerina, glutaraldeído, polietilenoglicol e perclorato de lítio. Estes filmes foram caracterizados por espectroscopia de impedância eletroquímica (EIS), microscopia eletrônica de varredura (SEM), espectrometria de reflexão total atenuada no infravermelho com transforma de Fourier (ATR-FTIR), termogravimetria (TG). Os resultados mostraram que os biofilmes com quantidades mais elevadas de perclorato de lítio possuem valores maiores de condutividade e as diferenças morfológica e molecular foram observadas como sendo um resultado das proporções adicionadas dos compostos em cada uma das rotas de preparação.
\end{abstract}

In the current work, conductor biofilms were synthesized by means of solutions of $100 \mathrm{~mL}$ of water with $3 \mathrm{~g}$ of starch from cassava (Manihot esculenta Crantz) and different amounts of glycerin, glutaraldehyde, polyethyleneglycol and lithium perchlorate. These biofilms were characterized through electrochemical impedance spectroscopy (EIS), scanning electronic microscopy (SEM), attenuated total reflectance Fourier transform infrared spectroscopy (ATR-FTIR) and thermogravimetry (TG). Results showed that biofilms with higher amount of lithium perchlorate portray higher values of conductivity and morphological and molecular differences could be observed as a result of the added proportions of the compounds in each one of the trials.

Keywords: biofilms, cassava starch, solid electrolyte, conductivity

\section{Introduction}

Polymeric materials obtained from renewable sources have gained attention and interest in recent years in both scientific communities and industrial sectors because of their applicability in a number of industrial sectors. Differently from other traditional synthesized biochemical materials, biopolymers or bioplastics have an interesting set of advantages namely the reduced environmental impact, the low consumption of energy in their production, their renewable resource status, the potential to add value to by-products and waste coming from industries and their particular biodegradability. ${ }^{1-4}$ Their applications are several and varied: they may be found as parts of wrappings, medical materials, reinforced plastics, edible films and others. ${ }^{5-7}$

*e-mail: alvaro.arrieta@upbmonteria.edu.co
Nowadays there is a trend towards the synthesis of biofilms possessing conducting properties in order to be used in electronic and medical industries. Because of their characteristics, these biofilms or bioplastic conductors are currently introduced as solid polymeric electrolytes (SPEs), a new type of ionic solid used in the development of batteries, diodes, electrochemical capacitors, sensors, electrochromic devices, fuel cells, actuator mechanisms etc. They have the quality of being ionic conduction materials, ${ }^{5,8,9}$ which is caused by exclusive properties such as suitable electrode/electrolyte contact, a simple preparation to obtain different forms and their mechanical and adhesive qualities. ${ }^{10,11}$ Recent research conducted by ARS (Agricultural Research Service) in Peoria (USA) has been discovered that polysaccharides such as starch found in plants can perform the afore mentioned functions. These polysaccharides are modified through an ongoing plasticization and doping process, and highly-conductive 
films are obtained. ${ }^{12}$ Starch-based electrolytes which are rich in amilopectine, plasticized in glycerol and with lithium salt content have been currently proposed as solid polymeric electrolytes suitable for different applications, being one of the most promising the one of artificial muscles. ${ }^{11}$

Cassava (Manihot esculenta Crantz), one of the main sources of industrial starch, is farmed in tropical countries in South America such as Brazil, Paraguay and Colombia, as well as in Central America and the Greater Antilles (Cuba, Haiti and the Dominican Republic), ${ }^{13}$ which makes it an abundant and cheap source of starch. ${ }^{14}$ Over the last two decades, the Colombian government in association with other international institutions has been promoting the improvement and transformation of cassava starch through the investing in a number of agroindustrial projects in different regions of the country in order to rise the levels of rural development and profits for farmers. ${ }^{13}$

The goal of this research is focused on obtaining a conducting biofilm from cassava starch for its latter application on artificial muscles; for such a reason biofilms must possess good conductivity, flexibility and stability when facing traction. With that in mind, trials with different plasticizers in different concentration levels were made. Variations in the concentration of dopant were also made in order to study such an effect over the properties of the resulting film.

\section{Experimental}

Cassava starch was obtained from the Venezuelan variety Manihot esculenta Crantz currently farmed in the department of Cordoba (Colombia), by using the method that comprises the basic operations of washing, peeling, grating, straining, decantation, drying and grinding. Glycerol (GLY), glutaraldehyde (GLU), polyethyleneglycol (PEG) and lithium perchlorate (LP) were provided by Sigma-Aldrich.

Conducting biofilms were prepared by means of the casting technique. Those were prepared at $\mathrm{pH} 9.0$ and $70{ }^{\circ} \mathrm{C}$ from the mixture of cassava starch $(3 \mathrm{~g}$ of starch 100 Milli-Q water) with different compounds featured in the experimental design which is shown in Table 1. The addition of GLY, GLU, PEG and LP was performed at room temperature and with constant stirring. Solutions were kept at $70.0 \pm 5.0^{\circ} \mathrm{C}$ with controlled temperature during

Table 1. Taguchi experimental desing for different proportions of the compounds (GLY, GLU, PEG and LP) used and the consistency physical and conductivity obtained in the conducting biofilms

\begin{tabular}{|c|c|c|c|c|c|c|}
\hline \multirow[t]{2}{*}{ Assay number } & \multicolumn{4}{|c|}{ Factor (compound amount in g) } & \multicolumn{2}{|c|}{ Responses } \\
\hline & Gly & Glu & PEG & $\mathrm{LiClO}_{4}$ & Consistency & Conductivity / $\left(\mathrm{S} \mathrm{cm}^{-1}\right)$ \\
\hline 1 & 0 & 0 & 0 & 0 & no pass & - \\
\hline 2 & 0 & 1 & 1 & 0.5 & no pass & - \\
\hline 3 & 0 & 2 & 2 & 1.5 & no pass & - \\
\hline 4 & 0 & 3 & 3 & 3 & no pass & - \\
\hline 5 & 0 & 5 & 5 & 5 & no pass & - \\
\hline 6 & 1 & 0 & 1 & 1.5 & no pass & - \\
\hline 7 & 1 & 1 & 2 & 3 & no pass & - \\
\hline 8 & 1 & 2 & 3 & 5 & no pass & - \\
\hline 9 & 1 & 3 & 5 & 0 & no pass & - \\
\hline 10 & 1 & 5 & 0 & 0.5 & no pass & - \\
\hline 11 & 2 & 0 & 2 & 5 & no pass & - \\
\hline 12 & 2 & 1 & 3 & 0 & no pass & - \\
\hline 13 & 2 & 2 & 5 & 0.5 & no pass & - \\
\hline 14 & 2 & 3 & 0 & 1.5 & pass & $2.5 \times 10^{-4}$ \\
\hline 15 & 2 & 5 & 1 & 3 & pass & $8.1 \times 10^{-3}$ \\
\hline 16 & 3 & 0 & 3 & 0.5 & no pass & - \\
\hline 17 & 3 & 1 & 5 & 1.5 & no pass & - \\
\hline 18 & 3 & 2 & 0 & 3 & pass & $8.1 \times 10^{-3}$ \\
\hline 19 & 3 & 3 & 1 & 5 & no pass & - \\
\hline 20 & 3 & 5 & 2 & 0 & pass & $1.6 \times 10^{-6}$ \\
\hline 21 & 5 & 0 & 5 & 3 & no pass & - \\
\hline 22 & 5 & 1 & 0 & 5 & no pass & - \\
\hline 23 & 5 & 2 & 1 & 0 & no pass & - \\
\hline 24 & 5 & 3 & 2 & 0.5 & no pass & - \\
\hline 25 & 5 & 5 & 3 & 1.5 & no pass & - \\
\hline
\end{tabular}


$15 \mathrm{~min}$, for their later placement on polytetrafluoroethylene (Teflon ${ }^{\circledR}$, DuPont) trays on which they left sitting for $48 \mathrm{~h}$ at $70{ }^{\circ} \mathrm{C}$.

The polymeric samples resulting from the trials of the experimental design (Taguchi method) were assessed by taking into account two criteria: physical consistency and conductivity. For such reason, concentrations of the three plasticizings and the dopant (4 variables) were used as variables and each of those was defined in four levels.

The assessment of the physical consistency of the films was made up by establishing if the film was broken or not when tested in a hand traction trial at a distance of $1 \mathrm{~cm}$. If the film was not broken, it overcame the consistency criterion and then its conductivity was tested. The diameter of the produced biofilms was $485 \mu \mathrm{m}$. The other desirable features in films such as consistency, physical homogeneity and flexibility were tested by visual inspection of the samples and performed seven days after the making of the films which is the estimated amount of time for solvent total removal and therefore the sample is considered as stable.

Ionic conductivity was performed in an electrochemical cell made up by the electrolyte sample connected between two stainless iron electrodes. Conductivity measures $(10 \mathrm{mV}(\mathrm{rms}) \mathrm{ac})$ were determined at room temperature by means of the electrochemical impedance spectroscopy (EIS) in a frequency range of $1 \mathrm{~Hz}$ to $1 \mathrm{MHz}$ with a potentiostat/ galvanostat/FRA 2263 PARSTAT (Princeton Applied Research). Measured samples for ionic conductivity were about $1 \mathrm{~cm}^{2}$ and $480 \mu \mathrm{m}$ thick.

Scanning electronic microscopy (SEM) was performed with a JEOL-6380LV microscope with energy of $20 \mathrm{kV}$. Samples were covered with a fine layer of gold. Attenuated total reflectance Fourier transform infrared spectra (ATR-FTIR) were recorded at $20{ }^{\circ} \mathrm{C}$ by using a Nicolet Series 6700 infrared spectrophotometer which was equipped with ATR type IIA crystal diamond, a wavelength range of 4000-400 $\mathrm{cm}^{-1}$ and spectral resolution of $4 \mathrm{~cm}^{-1}$. All the spectra were averaged over 64 sweepings.

The thermogravimetry analysis (TGA) were conducted in a TG/STDA 851e Mettler Toledo at $10{ }^{\circ} \mathrm{C} \mathrm{min}{ }^{-1}$ from room temperature to $600{ }^{\circ} \mathrm{C}$. Trials were made under nitrogen atmosphere with flow of $30 \mathrm{~mL} \mathrm{~min}^{-1}$ and sample amount of $7 \mathrm{mg}$ approximately.

\section{Results and Discussion}

Conducting biofilms featured variable physical characteristics due to the use of different proportions of the compounds for each trial. As it is shown in Table 1, only samples $14,15,18$ and 20 portrayed the desirable characteristics such as consistency, physical homogeneity and flexibility.

In the making process it could be observed that environmental conditions (humidity and temperature) affect significantly the consistency criterion for the films after their processing. At the moment of being prepared, they turn flexible during the first seven days, but after this period of time, they stabilize, and most of them portray small resistance to breaking after they are subjected to the hand traction trial. This behavior was also witnessed by Forssell et al. ${ }^{15}$ with some films obtained from starch. The addition of plasticizings increases the flexibility of the films because of their capacity to reduce the inner hydrogen bonds between polymeric chains, and also increase the molecular space. Figure 1 shows biofilm obtained in trial 18 , one of the samples that best overcame the consistency criterion.

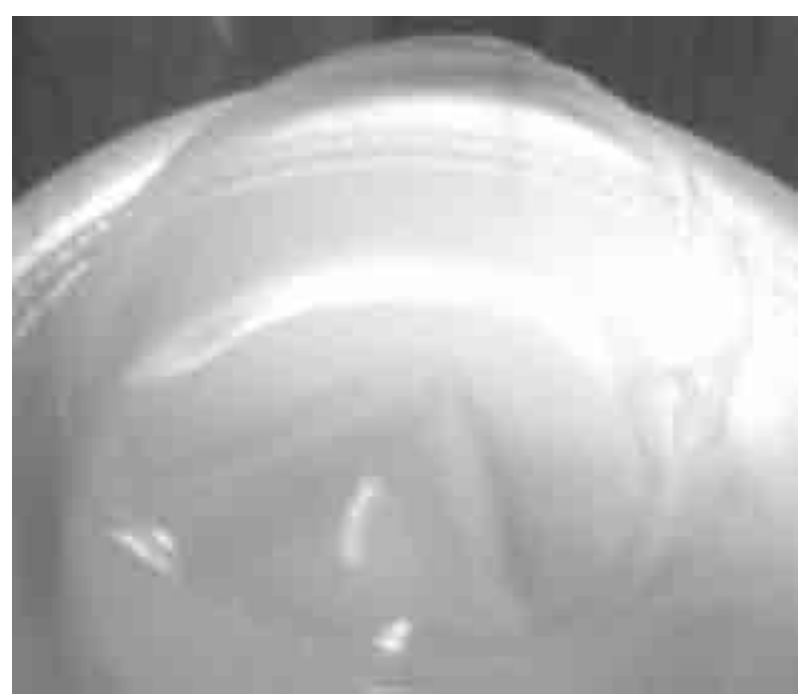

Figure 1. Conducting biofilms obtained from assay No. 18.

Physical appearance was another important aspect which portrayed changes as days passed by. At the moment of making, biofilms are transparent, but from the third day on they become opaque (yellowish) and exhibit a remnant liquid on the surface. This phenomenon occurs because the plasticizing concentration exceeds the compatibility in the polymer which causes separation of the phases and physical exclusion of the reactant as also observed by Laohakunjit and Noomhorm in previous work. ${ }^{16}$

In SEM micrographs (Figure 2), differences in film microstructures can be observed. Starch granules on their surface were noticed in most of the films which did not pass the consistency criterion portrayed (micrographies $b$ and f). Discontinuous phases were also perceived indicating the non-existence of a starch plasticized matrix (micrography a). 

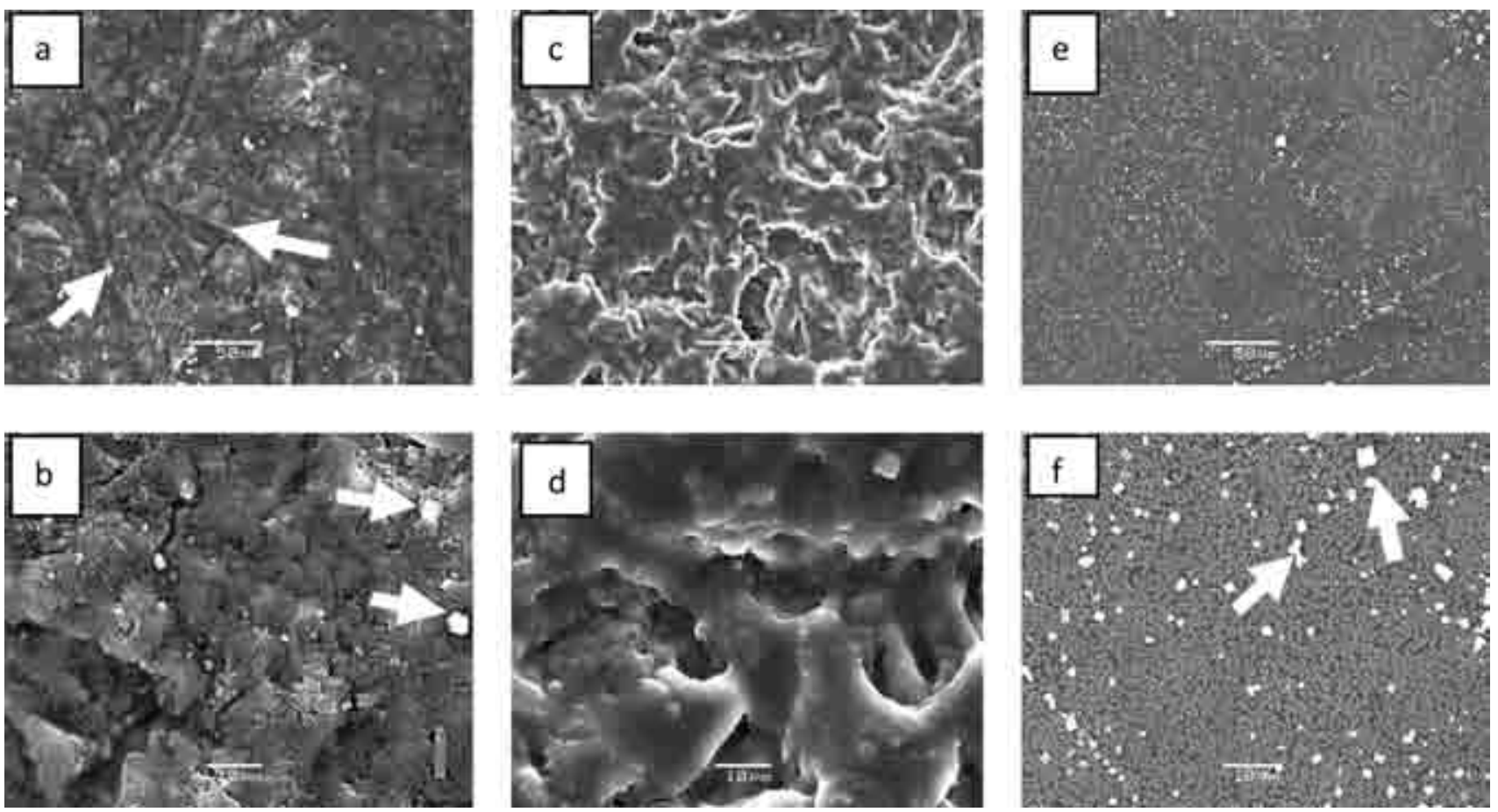

Figure 2. SEM micrographs of conducting biofilms of assays: (a) No. 3 at $50 \mu \mathrm{m}$, (b) No. 3 at $10 \mu \mathrm{m}$, (c) No. 4 at $50 \mu \mathrm{m}$, (d) No. 4 at $10 \mu \mathrm{m}$, (e) No. 10 at $50 \mu \mathrm{m}$ and (f) No. 10 at $10 \mu \mathrm{m}$.

On the other hand, those samples which did pass the consistency criterion (trials $14,15,18$ and 20) portrayed in their micrographies (Figure 3) flat and continuous surfaces demonstrating that most of the starch granules were partially destroyed and integrated into a plasticized matrix.
Figure 4 shows the diagrams of the imaginary impedance $\left(\mathrm{Z}_{\text {imag }}\right) v s$. the real impedance $\left(\mathrm{Z}_{\mathrm{re}}\right)$ of the EIS obtained for conducting biofilms which did pass the consistency criterion (trials $14,15,18$ and 20). Ionic conductivity of the sample $(\sigma)$ was calculated by using the equation $\sigma=\mathrm{L} /\left(\mathrm{R}_{\mathrm{b}} \mathrm{A}\right)$,
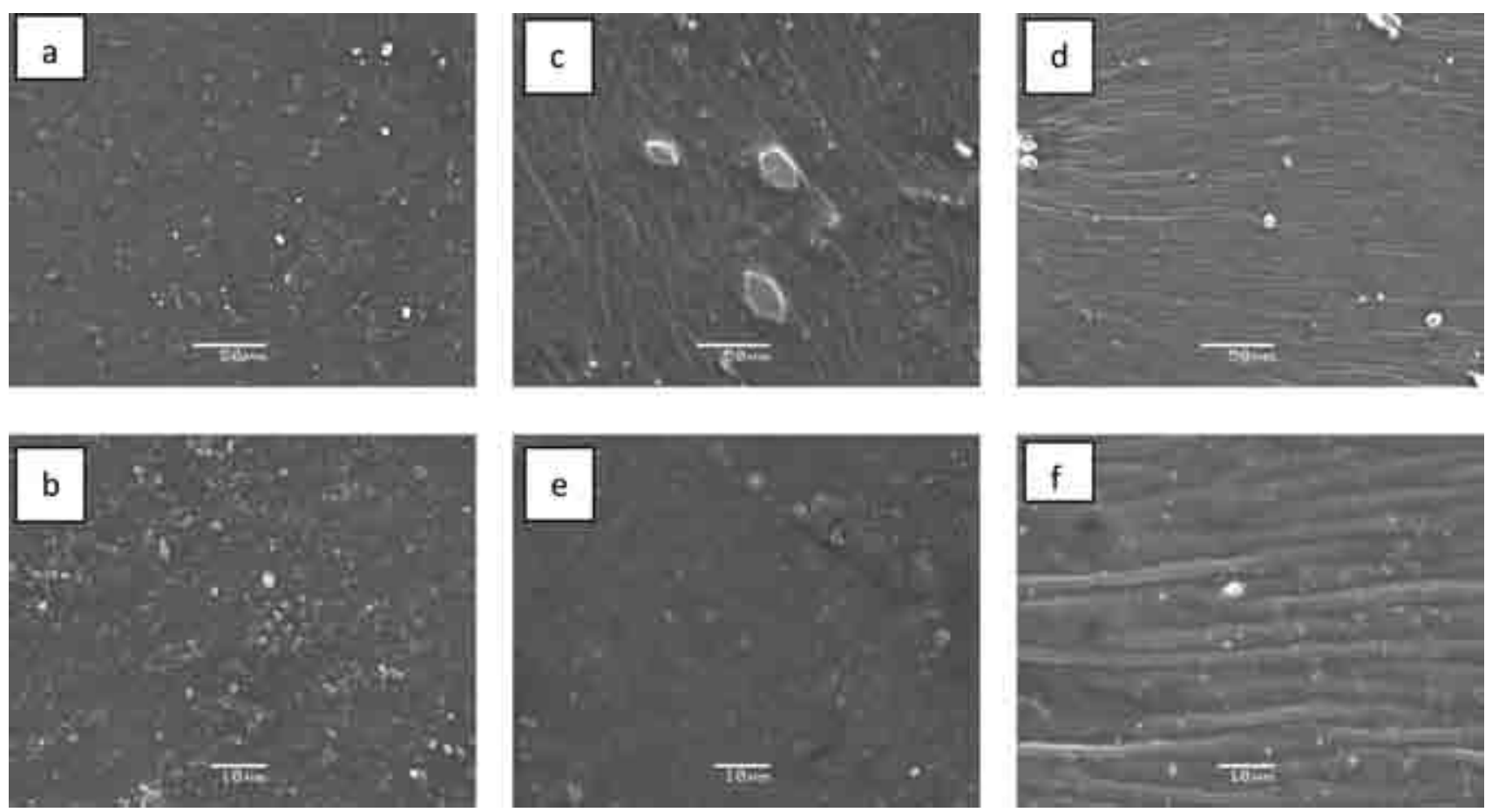

Figure 3. SEM micrographs of conducting biofilms of assays: (a) No. 14 at $50 \mu \mathrm{m}$, (b) No. 14 at $10 \mu \mathrm{m}$, (c) No. 15 at $50 \mu \mathrm{m}$, (d) No. 18 at $50 \mu \mathrm{m}$, (e) No. 18 at $10 \mu \mathrm{m}$ and (f) No. 18 at $10 \mu \mathrm{m}$. 
in which $\mathrm{L}$ is the film thickness, $\mathrm{A}$ is the surface area of the film and $R_{b}$ is the electrical resistance of the material calculated by the intercept in the high frequency region with the real $\mathrm{z}$ axis. ${ }^{17}$ Conductivity reaches $8.1 \times 10^{-3} \mathrm{~S} \mathrm{~cm}^{-1}$ for samples 15 and 18 which contain $3 \mathrm{~g}$ of lithium perchlorate. The conductivity values observed are close to reported in the literature to similar materials. ${ }^{18}$ It could be observed that samples with higher conductivity are those which actually have a higher content of lithium perchlorate in their formulation. The sample whose amount of lithium perchlorate is less than $3 \mathrm{~g}$ (trial 20) portrayed a small conductivity, $c a$. $1.6 \times 10^{-6} \mathrm{~S} \mathrm{~cm}^{-1}$. According to Rajendran et al., ${ }^{19}$ ionic conductivity of a polymeric electrolyte depends on the concentration of the conducting species and their mobility.

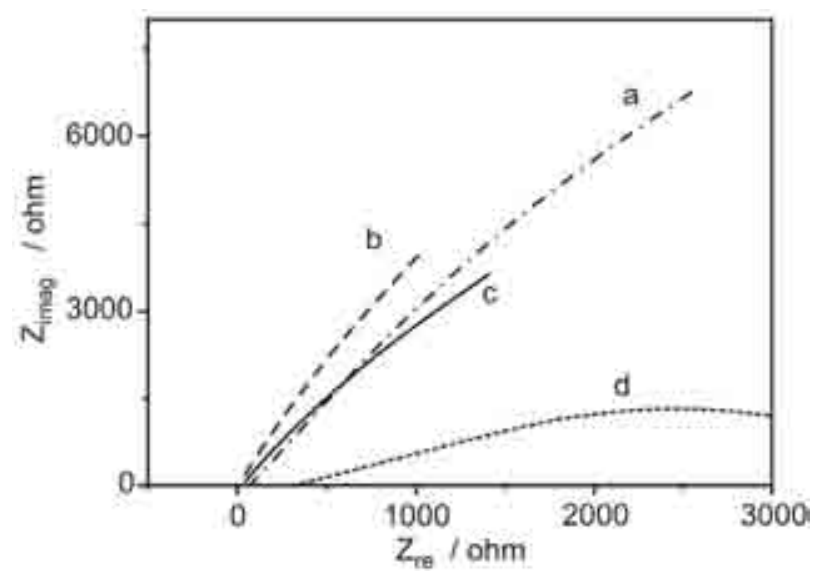

Figure 4. Impedance spectroscopy response of conducting biofilms of assays: (a) No. 14, (b) No. 15, (c) No. 18 and (d) No. 20.

With the purpose of identifying the interactions which occurred in the polymeric matrix obtained from cassava starch, analysis FTIR with ATR was used. In Figure 5 vibrations at $1020 \mathrm{~cm}^{-1}$ related to stretching on the $\mathrm{C}-\mathrm{O}$ bonds of the $\mathrm{C}-\mathrm{O}-\mathrm{C}$ group and at 1080 and $1153 \mathrm{~cm}^{-1}$ assigned to stretching on the $\mathrm{C}-\mathrm{O}$ bond of the $\mathrm{C}-\mathrm{O}-\mathrm{H}$ group of starch could be observed. The bands observed at 1642 and $2929 \mathrm{~cm}^{-1}$ were associated to water present in the conducting biofilm and the stretching on the $\mathrm{C}-\mathrm{H}_{2}$ bond of the starch anhydroglucose ring, respectively. The observed vibration at $3339 \mathrm{~cm}^{-1}$ is related to $\mathrm{OH}$ stretching of water and glucose.

Figure 5 also shows the changes produced in the spectrum due to the addition of compounds in the trials. When two components get in contact, physical mixtures and chemical interactions, the latter ones affected by the changes in the characteristic vibrations of spectra. ${ }^{20}$ The plasticizings in the films make hydrogen bridges with the starch molecules which weaken the strong action of both inter and intra molecular hydrogen bonds, thus reducing

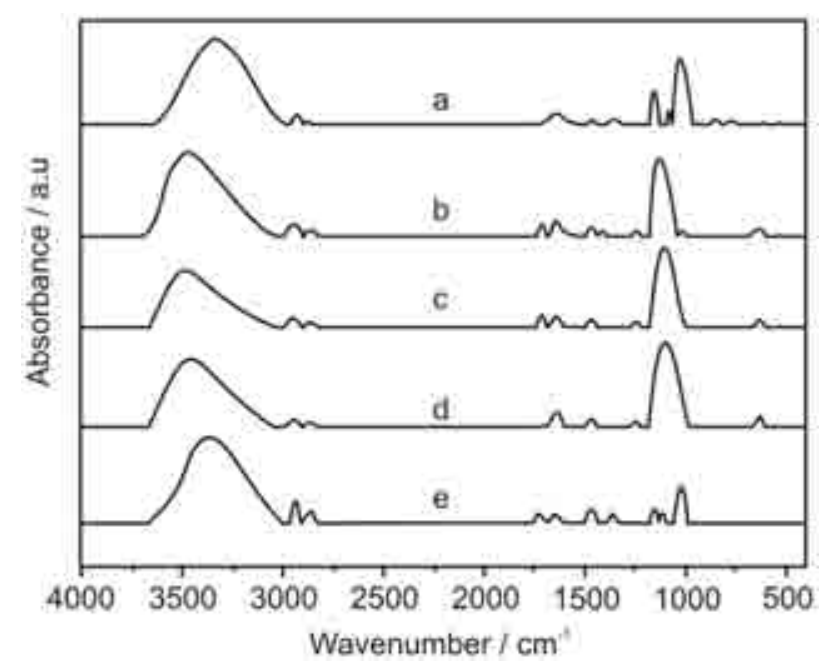

Figure 5. ATR-FTIR spectra of conducting biofilms of assays: (a) No. 1, (b) No. 14, (c) No. 15, (d) No. 18 and (e) No. 20.

the interaction between the amylase and amilopectine and making the film flexible. The formation of bonds between plasticizings and starch are directly related to the changes in the number of wave by stretchings in the respective bands of the functional groups. Changes in the characteristic vibrations of starch could be observed through the spectra matching trials $14,15,18$ and 20. According to Silverstein and Webster, ${ }^{21}$ the formation of hydrogen bonds disturbs the constant force of the involved groups, and thus the frequency of deformities is altered.

A new band is perceived between 1709 and $1712 \mathrm{~cm}^{-1}$ related to the carbonyl group of the cross agent in this study. In samples 15 and 20 whose gluteraldehyde concentrations are greater than the rest of the analyzed samples, a higher relative intensity on this band was observed. The intensity of an absorption band is proportional to the concentration of the components which originate such band.

The complex interaction between ionic transport and interionic interactions in the conducting biofilms can be observed. The dissociation of lithium salt is an important parameter which determines the ionic conductivity of the electrolyte. On this particular case, dissociation of lithium perchlorate added to the mixtures raises the mobility of the lithium ion and the polymer becomes more conducting. The band between 620 and $640 \mathrm{~cm}^{-1}$ is assigned to free ion vibration mode $\left(\mathrm{ClO}_{4}\right)^{-}$. When the concentration of perchlorate lithium salt is increased in the mixture, the frequencies and intensities of the strongest bands change. This fact indicates that the introduction of salt in the biopolymer changes the molecular interactions. An additional stretching vibration of the hydroxyl group detected near to $3250 \mathrm{~cm}^{-1}$ in each polymeric mixture can be traced back to the stretching vibration of the $\mathrm{O}-\mathrm{H}$ bond 

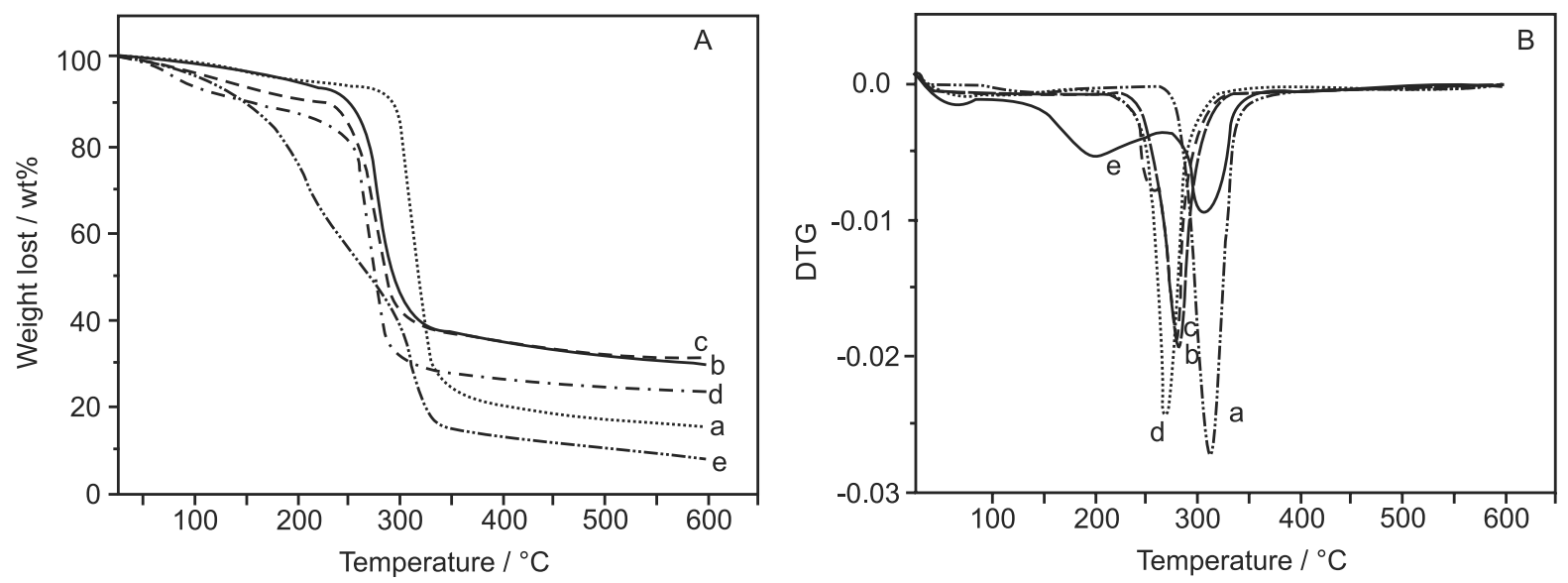

Figure 6. TG (A) and DTG (B) responses of conducting biofilms of assays: (a) No. 1, (b) No. 14, (c) No. 15, (d) No. 18 and (e) No. 20.

of the starch hydroxyl linked by the hydrogen to perchlorate ion $\left(\mathrm{ClO}_{4}\right)^{-}$. These changes in the infrared spectra are related to the interactions between the hydroxyl group and the ions. With mild plasticizing contents and cross agent, dissociation of lithium salt can be improved in the electrolyte and therefore the number of load transporters in the system is also raised.

The thermogravimetric analysis (TGA) was performed in order to detect the thermal stability of the conducting biofilm (Figure 6 (A)). The decomposition temperature appeared in a maximum proportion of mass loss, that is to say, the peak temperature shown in DTG curves (Figure $6(\mathrm{~B})$ ).

In Figure 6 (A), the biofilm solely made by starch and water (trial a) can be observed having a decomposition phase around $312{ }^{\circ} \mathrm{C}$ which matches the temperature of thermal depolymerazation of the polysaccharide. ${ }^{22}$ Differently from the biofilm solely made by starch, the mixtures made by plasticizings and cross agents and dopant has a lower thermal stability temperature which is reflected in the reductions of the decomposition temperature. This phenomenon may be related to the reduction of some of the components in the conducting biofilms which have a better thermal stability as starch. Similar research work presented how the addition of certain components in the formation of biofilms can cause starch degradation and influence the thermal stability of the material. ${ }^{23}$

\section{Conclusions}

In this work, conducting biofilms were synthesized from cassava starch and water, mixed with glycerol, glutarldehyde and polyethylenglycol and lithium perchlorate in different proportions. Through the assessment of the physical consistency it was possible to choose the biofilms which would be subject to the spectroscopy trials of electrochemistry (EIS), SEM, ATR-FTIR, TG and DTG. According to the results obtained, it was found out that the synthesized conducting biofilms possessed variable physical characteristics resulting from different amounts of added compound, which do not only significantly influence on morphology, but also on conductivity, molecular structure and thermal stability of the material. The plasticizing form hydrogen bridges with the starch molecules, apart from different plasticizing concentrations also produces movements in the bands of the recorded infrared spectra. Conducting biofilms obtained from cassava starch, make up a new and environmentally, friendly technology and with big potential to be used in different industrial sectors.

\section{Acknowledgements}

Financial support from COLCIENCIAS-SENA, Universidad Pontificia Bolivariana and Comisión Departamental de Ciencia y Tecnología (CODECyT) of Cordoba Department (Colombia).

\section{References}

1. Baillie, C. A.; Compos. Sci. Technol. 2003, 63, 1223.

2. Parra, D. F.; Tadini, C.C.; Ponce, P.; Lugao, A.B.; Carbohydr. Polym. 2004, 58, 481.

3. Okada, M.; Prog. Polym. Sci. 2002, 27, 87.

4. Averous, L.; Boquillon, N.; Carbohydr. Polym. 2004, 56, 11.

5. Finkenstadt, V. L.; Appl. Microbiol. Biotechnol. 2005, 67, 735.

6. Huang, X.; Netravali, A.; Compos. Sci. Technol. 2007, 67, 2005.

7. Magalhães, N.F; Andrade C.T; J. Braz. Chem. Soc. 2010, 21, 202.

8. Bakhshi, A. K.; Bull. Mater. Sci. 1995, 18, 469.

9. Zhang, Q. M.; Furukawa, T.; Bar-Cohen, Y.; Scheinbeim, J.; Mater. Res. Soc. Symp. Proc. 2000, 600, 1. 
10. MacCallum, J. R.; Vincent, C. A., eds. In Polymer Electrolyte Reviews, Elsevier: London, 1987 and 1989.

11. Suszkiw, J.; Agric. Res. Mag. 2005, 53, 10.

12. Lopes, V. S.; Dragunski, D. C.; Pawlicka, A.; Donoso, J. P.; Electrochim. Acta 2003, 48, 2021.

13. FAO/WHO Expert Consultation; Proceedings of the Validation Forum on the Global Cassava Development Strategy, FAO: Rome, 2000.

14. Matsui, K. N.; Lorotonda, F. D. S.; Paes, S. S.; Luiz, D. B.; Pires A. T. N.; Laurindo, J. B.; Carbohydr. Polym. 2004, 55, 237.

15. Forssell, P. M.; Hulleman, S.H.D.; Myllarinen, P. J.; Moates, G. K.; Parker, R.; Carbohydr. Polym. 1999, 39, 43.

16. Laohakunjit, N.; Noomhorm, A.; Starch/Stärke 2004, 56, 348.

17. Vieira, D. F.; Avellaneda, C. O.; Pawlicka, A.; Electrochim. Acta 2007, 53, 1404.

18. Lopes, L. V. S.; Dragunski, D. C.; Pawlicka, A.; Donoso J. P.; Electrochim. Acta 2003, 48, 2021.
19. Jacob, M.; Prabaharan, S.; Radhakrishna, S.; Solid State Ionic 1997, 104, 105.

20. Guan, Y. L.; Liu, X. F.; Zhang, Y. P.; Ya, K. D.; J. Appl. Polym. Sci. 1998, 67, 1965.

21. Silverstein, R. M.; Webser, F.X.; Kiemle, D. J.; Identificação Espectrométrica de Compostos Orgânicos, 6a. ed., LTC: Rio de Janeiro, Brasil, 2001.

22. Ma, X.; Chang, P. R.; Yang, J.; Yu; J.; Carbohydr. Polym. 2009, 75,472 .

23. Ning, W.; Xingxiang, Z.; Haihui, L.; Jianping, W.; Carbohydr. Polym. 2009, 77, 607.

Submitted: July 20, 2010

Published online: February 22, 2011 